\title{
The School-to-Prison Pipeline, Youth from Diverse Families, and the Politics of Educational Policy and Practice: A Call to Educate, not Incarcerate
}

\author{
Suniti Sharma \\ Saint Joseph's University \\ Philadelphia, USA
}

\begin{abstract}
In this article, I present a theoretical analysis of the school-to-prison pipeline in relation to youth from diverse families and the politics of educational policy and practice and call for equitable education without recourse to incarceration. First, by deconstructing historical documents, I highlight the philosophical and discursive production of the criminalization of youth from diverse families who do not conform to dominant norms of Western European tradition. Second, I juxtapose historical documents with contemporary events showing how current educational policies normalize the school-to-prison pipeline and subjugate youth from diverse families to exclude them from equitable education. Third, bearing witness to the ways youth resist socialization and exclusion, I recommend an interdisciplinary, multilevel socio-ecopol-edu approach calling upon policy makers, teacher educators, and researchers to develop new theoretical frameworks, policies, and practices for equitable education and social justice.
\end{abstract}

\section{Reality of the School-to-Prison Pipeline}

In the United States (U.S.), public education represents critical and systemic components of an institutional network that wields social, economic, and political power. As part of the public education system, schools participate in a process of socialization, a mechanism for institutional networking of educational policy, power, and practice. Educational research and policy, school discourse, and classroom practice institutionalize power informed by knowledge systems that stem from Western European Enlightenment's goals of rationality and universality as organizing principles for the reproduction of institutions and values embedded in them (Jacoby, 2008). The legacy of rationality and universality becomes transparent in educational policies such as the No Child Left Behind Act (United States Department of Education, 2001) and the Common Core State Standards (Council of Chief State School Officers, 2015) that 
standardize education as universal truth supporting a network for maintaining social, political, and economic power to predict, monitor, and control populations.

Standardization of education is a strategic agenda aligned with social, economic, and political discursive strategies for U.S. global power reflected in the discursive production of high-stakes testing, academic achievement, deficit perspectives, and school disciplining policies (Au, 2009). Implementation of educational policies designed within the goals of rationality and universality discursively position individual responsibilities and behaviors as variables to be modified and controlled. In practice, school implementation of policy and power situate youth from diverse families for generational crisis, unemployment, and incarceration through socializing practices that serve as pedagogies of punishment (Dohrn, 2002), class stratification of economic opportunities (Lipman, 2011), racial, ethnic, and gendered profiling (Meiners, 2007), and moral policing of cultural difference (Winn \& Behizadeh, 2011). This socialization process of education operating within a network of institutional policies, political power, and curriculum practice bring to reality the school-to-prison pipeline.

As policy makers, teachers, and administrators are normalized into the Enlightenment's principles and values, the social conditions reproduced, maintained, and created categorically position youth from diverse families on the margins of mainstream education to be labeled and sorted through the hidden curriculum of schooling - the prison pipeline. Visibility of the schoolto-prison pipeline takes precedence in criminal justice discourses in theory and practice but remains silent in educational policy, school discourse, and classroom practice. This culture of silence provokes questions about educational policy and its goals, the ideology of schools, and how political, economic, and penal power persist through the construction of categorical and hierarchical conceptual knowledge and its deployment.

\section{Philosophy of Contemporary Conditions for Youth Incarceration}

Contemporary conditions in education have transitioned from the goals of equal opportunities grounded in social justice to the service of economic theories and doctrines regulated through immigration and industrialization and put into practice through the legal system (Simmons, 2015). The legal, criminal, and judicial systems, as well as business interests, profit from the operationalization of juvenile crime and theories of rehabilitation mediated by professional knowledge systems such as psychology and education (Meiners, 2015). Supporting the contention, current networking repositions education from a humanist ideology of the welleducated citizen to the political economy of a cost-benefit package for college readiness, career advancement, and global performance.

A case in point is the state of Pennsylvania. In 2013, Pennsylvania policy makers instituted a reform model to overcome financial deficits and raise student performance by closing 24 urban public schools with long-term negative consequences, ranging from reduced community partnerships to educational disinvestment, with little or no improvement in academic performance (Jack \& Sludden, 2013). According to current financial reports, Pennsylvania spends an average of 37.40 per day for each student in public school; 343.17 per day for each student in the juvenile justice system; and a total of $\$ 1,201,116$ per day for 3500 incarcerated students (American Civil Liberties Union, 2015). Major cities such as Chicago, New York, and D.C. mirror the financial reform model of Pennsylvania public schools. The question then is: are some groups of students worth more in the juvenile justice system than in school? Under what 
School-to-Prison Pipeline and Youth from Diverse Families

conditions have policy makers, schools, and society constructed and sustained their truth claims to impose criminality on select groups of students?

To fully understand and answer these questions one must examine the philosophical context of how social institutions such as schools are entangled with the power, politics, and practice of punishment. According to Foucault (1972a), the epistemic-historical foundations of contemporary knowledge systems are grounded in Western European Enlightenment's vision for man's progress and prosperity emphasizing two interrelated philosophical themes that continue to be privileged in contemporary contexts: subject/object dualism and faith in universal reason. The subject/object dualism based on the belief that man is subject of all knowledge established several foundational binaries such as reason/emotion, mind/body and success/failure that are now taken-for-granted categories and hierarchies of privilege and exclusion in educational discourse. Similarly, man's faith in universal reason and the philosophical belief that objective truth/knowled ge derived from empirical science was considered key to progress and prosperity is a foundational concept privile ged in education.

The two themes converged in the Enlightenment vision built around discourses of the rational subject, scientific knowledge and objective truth to promote a binary hierarchical view of the world (Foucault, 1972a). Accordingly, the Western European male, rational subject represented the "self" as the epitome of man's progress and prosperity while anyone outside this construct was condemned and excluded as the irrational "other" (Said, 1978). Continuing this philosophical lineage, progress of mankind, imperialist domination, construction of diversity and difference as the deficit "other," subjugation of histories and cultures of non-Western people, and the use of knowledge to deploy power over "others" continue to play out in multiple sites, including education. The legacy of the Enlightenment is visible in the network of historical policies that criminalize and exclude minority populations from the right to the ballot; prevent economic growth to reassign them as cheap prison labor; and deny minority youth from diverse families equitable education through the unwritten rules of socialization, thus normalizing the criminalization of diversity and difference in schools (Alexander, 2011).

Social institutions such as schools are vehicles of power and knowledge operationalizing the Enlightenment vision, discursively reproducing categories, binaries, and hierarchies that rationalize privilege and exclusion, by this means, sustaining discrimination in policy, practice, and agendas. Educational policies and school practices signify there is a deep divide between the social and institutional structures of educational policy and practice and the schooling experiences of youth from diverse families, communities, and cultures (Sharma, 2010). The divide evidences the failure of education when the school-to-prison pipeline is normalized as a practice for excluding select student populations and controlling demographic changes in public education. Analyses of how crime is insidiously written into school discourse is evident in standardization and disciplinary policies such as the NCLB and Zero Tolerance deployed in schools, naming education as a major player in criminalization of youth who do not socialize into dominant cultural norms of race, class, gender, sexual orientation, religion, language, family, and parenting, among other forms of diversity. The outsourcing of discipline to law enforcement or controlling student populations in the name of zero tolerance is enactment of educational policy implemented through institutional power and practice.

By redefinition, the school-to-prison pipeline is a network of educational policies that erode social justice in schools by deploying discrimination against youth from diverse family backgrounds and positioning them for criminal careers, consequentially terminating their right to equitable education. Once in the prison pipeline, most students do not return to public education, 
drop out of school, or return to prison as adults (Sullivan, Klingbeil, \& Van Norman, 2013). The discursive network of standardization of knowledge, disciplining of behaviors, and control and punishment of diversity and difference, is an example of the school system using its policypower to operationalize the school-to-prison pipeline. According to Foucault (1972a; 1972b), power is both structural and dynamic; therefore, discipline and control generate resistance to the established internal order of institutions by creating sites such as the classroom where the struggle for power is a complex and continuous process.

\section{Technologies of Power and Knowledge}

In his seminal work on the genealogy of prisons, Foucault (1977) calls these discursive networks technologies of power and knowledge that produce subjects as objects to be subjugated. Foucault challenges the Enlightenment's taken-for-granted truth-claims, deconstructing the philosophical presuppositions and historical biases embedded in contemporary knowledge systems. In Discipline and Punish, Foucault maps the history of the contemporary prison system as an institutional network deploying technologies of disciplinary power and knowledge for segregating those who do not conform, controlling their behaviors, and subjecting them to normalization into incarceration. Foucault peels layers of social, penal, scientific, medical, and institutional discourse to show how the rational universal subject is created and what is arbitrarily constructed as its binary opposite: the delinquent or criminal subject. Disrupting traditional concepts of crime, criminal and criminality, and biases embedded in these concepts, Foucault argues that discipline and punishment is a discourse on the institutional control of knowledge and power-enabling categories, binaries, and hierarchies for subjugation of populations.

According to Foucault (1984), to understand contemporary knowledge systems one must trace the genealogy of their representation within concepts and how taken-for-granted concepts have been historically and discursively produced and privileged. For Foucault, genealogical analyses of the discursive history of a concept to highlight its present significance means critical inquiry that displaces traditional ontologies, epistemologies, and methodologies constructing the rational universal subject on the one hand and freeing the constructed subject from its philosophical subjugation, on the other. Foundational concepts emerging from philosophy, science, law, and medicine cannot be separated from the social context in which they are produced, drawing attention to the arbitrariness of universal ontologies and established epistemologies implicit in everyday interactions (1972a). For example, traces of a foundational concept such as race, once explained as a biological category evidencing genetic diversity, evolved into a eugenicist category for domination, subsequently viewed as a category producing inequities that need to be addressed-complex discourses present in everyday interactions illustrating how categorical assumptions become taken-for-granted school knowledge.

As a methodology, Foucauldian analytical methods are useful for making transparent the discursive epistemic history of the school-to-prison pipeline as problematic forms of philosophical, social, scientific, legal knowledge and the biases embedded reflected in contemporary educational policy and practice. In what follows, I analyze the school-to-prison pipeline in relation to youth from diverse families and the politics of educational policy, power, and practice. In order to contextualize my analysis, the next section consists of a brief review of interdisciplinary scholarship on the current social context of educational policy, school discourse, and classroom practice. Following the review, I analyze the epistemic-history of the 
School-to-Prison Pipeline and Youth from Diverse Families

school-to-prison pipeline. In so doing, my aim is threefold. First, by deconstructing historical documents, I highlight the philosophical and discursive production of the criminalization of diverse populations who do not conform to the dominant norms of Western European tradition. Second, I juxtapose historical documents with contemporary events to show how current educational policies actualize foundational practices by normalizing the school-to-prison pipeline as accepted means and measures for disciplinary action to subjugate youth from diverse families, simultaneously excluding them from quality education. Third, bearing witness to the ways youth resist socialization and exclusion, I recommend an interdisciplinary, multilevel socio-eco-poledu approach to developing new theoretical frameworks and policies for equity and social justice in teaching practice so that students from diverse families and communities experience equitable education.

\section{Research on Educational Policy and Disciplinary Practice}

History is replete with examples in which a policy is created to address inequities and empower diverse minority populations while another is set in motion to disenfranchise. For example, educational policy such as the No Child Left Behind Act of 2001, aimed at raising test scores of low-performing schools and zero-tolerance policies for keeping K-12 campuses free of violence have been instrumental in sorting students who do not conform to dominant cultural norms for the prison pipeline with disastrous consequences for their educational futures (Alexander, 2011). Rather than empower and educate, school policies address youth resistance to socialization with disciplinary actions leading to expulsion that increase the likelihood of dropping out of the education system, repeating grade levels, and being placed in alternative school settings, adversely affecting access to equitable educational opportunities (Advancement Project, 2010).

Most low-performing schools struggling to raise test scores are located in urban settings and serve poor and working-class minority communities, predominantly Black and Latino, who constitute a large percentage of criminalized youth. While minority youth represent 34 percent of the U.S. adolescent population, they represent 62 percent of youth experiencing disciplinary action for minor infractions and are processed into the school-to-prison pipeline with serious consequences for their educational futures (Children's Defense Fund, 2007). With 90,000 youth in juvenile prison, 10,000 cases pending adjudication, 4,100 in adult prisons, not counting youth in adult detention facilities, half-way homes, or awaiting placement after sentencing decisions (Snyder \& Sickmund, 2006), the option of prison time for young populations is a civil rights issue that calls for immediate political action from all stakeholders. With one child suspended from school every 3.5 seconds, dropping out of school every 20 seconds, and arrested every 32 seconds, the social, educational, and economic implications of the school-to-prison pipeline demand immediate attention of policy makers, teacher educators, teachers, and K-12 administrators (Children's Defense Fund, 2011).

Research findings from three largescale studies situate the context of educational policy, school discourse, and classroom practice in perspective, underscoring the socialization process of the school-to-prison pipeline. A statewide longitudinal study on the relationship between student success and school discipline policies examined data pertaining to all seventh-grade public school students across Texas in 2000, 2001, and 2002 (Fabelo, Thompson, Plotkin, Carmichael, Marchbanks, \& Booth, 2011). The study analyzed nearly one million students' school records to follow their academic trajectory for a six-year period, and simultaneously searched the state 
juvenile justice database to study school disciplinary history of students with juvenile records. The study found that, $60 \%$ of students in the study experienced school suspension or/and expulsion, or/and detention, which disproportionately affected minority students and significantly increased their chances of dropping out or being incarcerated. Significantly, out of those who experienced disciplinary action, only $3 \%$ of the decisions were based on student behaviors for which state law mandated suspensions and expulsions; the rest were discretionary subjective decisions of administrators and teachers based on minor classroom infractions. The study indicated Texas reflected a national trend on how school disciplinary policies are misused against minority youth and recommended policymakers across the country convene experts from education, juvenile justice, and child welfare systems to examine school policies and practices and develop effective and fair approaches to educate, not incarcerate.

While the Texas study examined student data, research on a nationally representative sample of 870 teachers examined their perceptions of how sorting youth through standardized testing and school discipline among other discourses contributed to their instructional effectiveness (Cogshall, Ott, \& Lasagna, 2010). According to the study, two discourses dominated teacher perceptions: the first being standardized tests and the second, classroom discipline. Of the total teachers who participated in the study, 57\% perceived "too much testing" as the biggest drawback to effective teaching; $46.5 \%$ perceived "too many kids with discipline and behavior issues" as the second major drawback. In all, $68.5 \%$ of the teachers believed removing students with "discipline problems" and having them "placed in alternative programs" would improve teaching effectiveness, and another $27 \%$ stated the move would be "somewhat effective" (p. 8-10). The study concluded there is a gap between teachers' perceptions that removal of students who do not comply promoted effective teaching and findings from research that report negative outcomes of removing students from the classroom in terms of their social, economic, and educational well-being. The study recommended bridging the gap between educational policy and teachers' classroom practice on the one hand and the effects of policy and practice on students and their families, on the other.

In addition to research on educational policy and school discourse, a national study on classroom practice of school discipline was conducted by the American Psychological Association's Zero Tolerance Task Force (Skiba, Reynolds, Graham, Sheras, Conoley, \& GarciaVazquez, 2006). Concerned about the effects of increased discriminatory action against minority students and students with disabilities, the task force examined the classroom practice of school disciplinary policies such as zero tolerance and its effects on youth development, its connection to the prison pipeline, and the impact of school disciplinary practices on students, families, and communities. The report concluded there is a significant increase in discretionary suspension and expulsion practices directed at students from diverse family backgrounds, communities, and cultures and provides evidence that implementing zero tolerance policies did not improve school discipline. The study noted disciplinary decisions depended on school philosophy and school personnel's perceptions of student attitudes and behaviors, resulting in practices that are ineffective and unfair.

Several studies substantiate school disciplinary decisions based on subjective labeling of students as 'good' or 'poor' learners or belonging to families considered 'normal' or 'dysfunctional' reflected the dominant cultural norms of teachers and administrators and is a primary contributing factor to the school-to-prison pipeline (Madkins, 2011). When teachers use their dominant cultural lens to create the conditions for socialization in their classrooms, they ignore the diversity among learners or misunderstand student resistance. Teachers' deficit lens 
School-to-Prison Pipeline and Youth from Diverse Families

toward diversity and disciplining of student resistance to socialization into school culture adversely affects youth from diverse family backgrounds (Achinstein \& Barrett, 2004). Each of the three illustrative studies and supporting scholarship raise questions about the social context of educational policy, school discourse, and classroom practice and their role in the disciplining of students who resist socialization.

\section{Historical and Contemporary Production of the School-to-Prison Pipeline}

Building upon the reviewed scholarship, in this section I present a Foucauldian analysis of historical and contemporary discourses on the school-to-prison pipeline in relation to diversity and difference, beginning with the social construction of a key concept in educationdelinquency - and its implied opposite, the norm. Foucault (1972a) writes that when studying the history of disciplinary systems of knowledge, one must deconstruct the history of its foundational concepts privileged through discursive networks of policy, power, and practice. According to Foucault, when studying foundational concepts, one is not led to the origins of objective knowledge; rather, one encounters an arbitrary discursive construction of conceptual knowledge with biases embedded within them. In order to study contemporary knowledge systems, Foucault suggests analyzing old documents of authority to flesh the discursive history of any taken-for-granted concept and ongoing "questioning of the document" to expose its power and presence in contemporary events (p. 6).

Using Foucauldian analysis, I deconstruct excerpts from historical documents taken from three different eras, including the discursive contexts in which they were produced, to show the social, scientific, and legal construction of the concept of delinquency as the binary opposite to what constitutes the norm. Historical excerpts are juxtaposed with contemporary events to illustrate the discursive networks of disciplinary knowledge systems that create, reproduce, and continue to maintain dominant power relations positioning the school-to-prison pipeline for youth from diverse families into educational policy, school discourse, and classroom practice.

\section{Social Discourses}

The first historical excerpt is taken from the progressive era when saving the child was considered a progressive approach to addressing social issues. One of the earliest child savers of the late $19^{\text {th }}$ and early $20^{\text {th }}$ century, Ernest Coulter (1871-1952) noted that children and youth who ran into the law were mostly victims of circumstance and that unruly behavior was due to parental neglect worsened by immigration, industrialization, and urban poverty. Below is one of the many contexts in which some of the earliest conditions of urban poor and working class were being criminalized and linked directly to delinquency. What is evident is the criminalization of urban spaces where the poor lived, a precursor to current conditions for criminalization of school spaces where the poor learn.

In the Children's Courts appear most clearly all the wrongs and inequalities whereby organized society, selfish and therefore ignorant, warps, thwarts and denies the future citizen. If the child is not to grow up to become a public charge, to fill the charitable institutions, the hospitals, the prisons, he must have light and air and space. Every crowded, ill-ventilated tenement is a tax upon the future. Each too, is a breeding ground of parental as well as juvenile delinquency; for each the community is responsible. It has the right, the privilege, the power to correct these evils, but it has not been attending to the conduct of its own affairs. These matters, the massing of the population, the 
regulation of immigration, the hygienic conditions of the tenements, rents and wages have been left in the hand of those, who profiting by congestion and extortion, have been blind to the rights of our neighbor and his child. (Coulter, 1913, p. xvi)

By bringing attention to structural conditions Coulter and fellow child savers, a subcategory of White progressives, established a social base for their humanist movement but also paved the path for criminalizing immigrant parents and youth from diverse communities for living in urban poverty. The movement was considered to have revolutionized the way society viewed urban poverty - undesirable social conditions in need of reform. Rather than address structural inequities, reform efforts included segregating poor urban communities from the safety of elite neighborhoods (Springer \& Roberts, 2011). Social and other forms of segregation made for easier policing and provided the impetus for the first juvenile court system in Chicago in 1899 , for processing youth from poor and working class urban communities into the prison pipeline. With the institution of the juvenile court and parens patriae policy, the government was given authority to intervene in parental rights and move children from their homes into state custody (Mack, 1909).

Policy intervention into improving structural and social conditions of urban youth or 'saving the child' turned into a project of reforming urban youth labeled juvenile delinquents, undermining parental authority and criminalizing families living in poverty. The merging of various discourses, diverse family experiences of immigration, industrialization, and urbanization are directly linked to "charitable institutions, the hospitals, the prisons." Articulating this new discourse that called for humanist responses to social problems, Child Savers viewed poverty and other related conditions as neglect, thus, initiating a social discourse that sorted youth and children based on the structural conditions of their families and communities that persists.

Contemporary events like gentrification, racially segmented urban neighborhoods, and school segregation replicate the social project of child savers to sustain the discursive production of delinquency and the criminalization and segregation of poverty. Social production of delinquency is reproduced and new discourses are added to delineate delinquency as social and moral conditions. The mission statement below evidences discourses that Foucault (1977) refers to as disciplinary technologies of power, knowledge, and control. The discursive shift from social to individual is critical. Structural and social conditions are recategorized in the new discourse of individual behavioral disorders to be addressed with behaviorist solutions such as moral education for rehabilitation in the juvenile justice system. Below is the mission statement of the juvenile correctional facility in the midWest where I taught for seven years as a full time English teacher:

At the Juvenile Academy the treatment process for examination, monitoring, and treatment begins upon arrival. Progress is noted constantly. We agree with Mr. Robert Ressler, former head of the FBI Behavioral Sciences Unit, and Dr. Stanton Samenow, chief psychologist for the federal St. Elizabeth's Hospital in Washington, DC, that many youth lack appropriate morals and ideals and develop ways of thinking and behaving detrimental to themselves and society. The treatment at Juvenile Academy focuses on providing good role models and high ideals for delinquent youth while simultaneously helping them correct the thinking errors which plague them and prevent them from reaching their goals. When pre- and post-treatment scores on the MMPI-A are compared we find that students consistently show a significant decrease in anger, depression, and suspiciousness, and also show clear increases in self-esteem and moral direction. Thus, 
School-to-Prison Pipeline and Youth from Diverse Families

both clinical impressions and clinical testing indicate the value of the treatment experience at Juvenile Academy. (Program Training Administrator, 2009)

As seen from the mission statement of the juvenile academy, in contemporary times professional systems of knowledge such as medical, psychological, and judicial, normalize social and structural inequities as a categories synonymous with criminality and a consequence of errant individual choice. Normalization of poverty as synonymous with criminality is not based on rational or objective knowledge; rather, it is an amalgam of historical practices of social exclusion that sort and segregate to reproduce and maintain the social, economic, and political order of power and privilege.

\section{Scientific Discourses}

In the order of things, scientific discourses hold extreme power dominating educational relations of privilege to categorically define racial discrimination and exclusion. Social, moral, and medical discourses merge with the scientific knowledge claims of social Darwinists who gave credence to the assumption that social problems were caused by innate criminal tendencies manifested in biological defects that were natural conditions of being non-European.

Accordingly, non-Europeans were labeled abnormal, feebleminded, and delinquent identified through racial categories. A study conducted by the Pennsylvania Institute of Feeble-Minded Children, (Kerlin, 1890) on "feeble-mindedness" of "the moral imbecile" as a condition for criminal behavior in children notes:

...if there existed a class of little children whose heredity and aberrations are such as to make them predestined inmates of our insane hospitals and jails, what an advance we would make in the diminution of crime and lunacy by a methodized registration and training of such children, or these failing, by their early and entire withdrawal from the community...that he shall not scathe our common stock with permanent taint in blood and morale. (Kerlin, 1890, p. 244-250)

Kerlin's "scientific" claims support Galton's (1881) eugenicist assumptions that biological conditions divided the human race into superior and inferior race, reinforcing categorical binaries and hierarchies of inclusion and exclusion in the name of empirical science. Similarly, Lombroso (1893), a giant figure in criminology in the nineteenth century, conducted scientific research to claim that physical features that do not conform to the norm are a born condition of degenerative behaviors. Lombroso advocated that instead of the law, science should identify, observe, and treat physical conditions considered abnormal, therefore criminal, as "the born criminal is without remedy, he must be continually confined, and allowed no provisional mercy or liberty..." (p. 44-45). As seen from the scholarship of Kerlin, Galton, and Lombroso, eugenicist discourses promoted the notion that Europeans were the norm and anyone outside the norm was "born" criminal, identifiable through physical features. Eugenicist claims to scientific knowledge normalized criminality of diverse populations justifying their continued exclusion from social, economic, and political life.

Norming of the individual continued as the field of education merged into the discursive networks of the twenty-first century. An example of how contemporary education sustains the discursive production of the norm and its binary opposite through scientific measurements and tests are evident in the construction of the Scholastic Aptitude Test (SAT) designed by Carl Brigham, one of the founders of psychometrics who chaired the College Board Commission from 1923 to 1926 and served as Professor of Psychology at Princeton (Lemann, 1999).

Brigham's (1923) A Study of American Intelligence forwards the eugenicist notion that the 
Nordic Race is intellectually superior, the Mediterranean Races inferior, and "Negroes" the most intellectually inferior race. In keeping with this hierarchy of racial categories, Brigham identifies immigration as an event to be controlled and proposed testing procedures to exclude non-Whites from higher education for maintaining the superiority of "American Intelligence." In the twentyfirst century the SATs constitute an important part of contemporary school discourse on scientific observation and standardized measurement for sorting students based on calibrated prediction and control of their educational futures.

Rather than examine social, structural, or systemic at-risk factors that marginalize and exclude minority youth from diverse backgrounds, schools focus on standardized tests and psychometrics to monitor performance levels and measure intelligence. Under the discourse on data and accountability, structural privilege and inequities are made invisible when variables are relegated as cognitive abilities such as high IQ, advance placements, and academic honors or deficiencies categorized as 'learning disabled' and 'remedial learner" (Baker, 2002). By establishing the conditions for offensive behavior and how to normalize those behaviors through notions of individual responsibility and behavioral reform, the school system frees itself of responsibilities toward equitable education and social justice, authorizing psychologists and law enforcement to evaluate behaviors, define problems, and design remedies. This transfer of educational responsibilities leaves the basis for systemic inequities, the socialization process of schools, and the construction of criminality unacknowledged, unexamined, and unaddressed.

In Foucauldian terms, educational institutions are technologies of power organized around sameness and differences conceptualized to monitor, control, and regulate populations who do not conform to dominant cultural norms through professional networks of disciplinary knowledge. Educational reform policies that mandate standardized testing for improving academic outcomes do not exclude certain groups from mainstream schooling per-se but conceptualize and reframe categories to define, exclude, marginalize, and set apart for treatment, therapy, and correction - exceptional, gifted, regular, and remedial and so on. What is considered equal opportunity in schooling, who falls into the mainstream dominant culture of schooling, and who must be excluded are, therefore, a priori constructs of professional systems of disciplinary knowledge such as philosophy, science, and education operationalized through an institutional network of policy, power and practice.

\section{Legal Discourses}

The legal authority within discourses propelled the social project of saving children and the scientific sorting to continue the reproduction under new conditions for criminalizing youth from diverse families and communities, now coded into the law. An excerpt in The Journal of Criminal Law, Criminology, and Police Science (Stullken, 1956), citing the Illino is Review Statute (1951, p. 190-221) illus trates this point:

Any male child who while under the age of 17 or any female child who while under the age of 18 violates any law of this state; or is incorrigible, or knowingly associates with thieves, vicious or immoral persons; or without just cause and without consents of its parents, guardian, or custodian absents itself from its home or place of abode, or is growing up in idleness or crime; or knowingly frequents a house of ill-repute; or knowingly frequents any policy shop or place where any gaming device is operated; or frequents any saloon or dram shop where intoxicating liquors are sold; or patronizes or visits any public pool room or bucket shop; or wanders about the streets in the night without being on any lawful business, or lawful occupation; or habitually wanders about 
School-to-Prison Pipeline and Youth from Diverse Families

any railroad yards or tracks or jumps or attempts to jump onto any moving train; or enters any car or engine without lawful authority; or uses vile, obscene, vulgar, profane or indecent language in any public place or about any school house; or is guilty of indecent or lascivious conduct. (p. 833)

As seen from the above excerpt, social and scientific discursive production of what constitutes the norm and its binary opposite, delinquency, is writ into legal discourse sanctioned in the language of moral policing of specific behaviors deemed undesirable. New discourses for sorting on the basis of age, gender, lifestyles, habits and behaviors such as loitering, profanity, and incorrigibility have been named to identify delinquency and structural inequities and disparate effects of immigration, industrialization, and urbanization are addressed by criminalization, sanctioned by law. Intervention of the law transforms social and scientific discourse into legal and penal writs and statutes for reforming youth and extends to disciplining and socializing their families as well.

Legal discourses supported the concept of delinquency by constructing and defining the norm for families and caregivers who were required to take care of children along specified guidelines for parenting. A law-abiding family would now conform to raising children within defined norms and specified regulations. Legislations were in place for protecting youth and children from what was considered parental neglect and for dealing with errant parents who did not abide by the social and legal norms of family and parenting (Mack, 1909). The Chicago legislation defined and imposed the norm for 'family' that was later replicated in other states. Imposition of family norms gave rise to a network of related services such as guidelines for lawful parenting, child protection laws, detention homes, foster care, state custody of children, and juvenile prisons for children and neglected youth. By the twenty-first century, the network of related services encompasses public education, encroaches on parenting rights, and operationalizes discriminatory school discipline - the historical and discursive production of the school-to-prison pipeline.

Historical and discursive production of the school-to-prison pipeline persists in contemporary discourses, namely, educational policies such as NCLB Act of 2001, Zero Tolerance policies, and Gun-Free Schools Act of 1994 reauthorized by the NCLB Act of 2001. The Gun-Free Schools Act directs K-12 schools receiving federal money to maintain zero tolerance for campus violence by expelling students bringing firearms to school. While keeping schools free from weapons, drugs, and any form of violence is not being contested, research indicates school safety policies include disruption and a host of behaviors subjectively deemed violation of school conduct and classroom rules (Skiba et al., 2006). Embedded in the practice of zero tolerance for disruption and unruly behaviors is the discourse on deficit parenting and neglected youth, mobilizing a network of related services such child protection laws, foster care services, youth detention homes, and the prison-pipeline. Teachers' subjective evaluations emerging from deficit perspectives toward diversity set in motion discriminatory implementation of educational policies for criminalizing youth behaviors. If incorrigibility, idleness, and profanity were made punishable in 1956; by 2015, disruption, insubordination, and potential threat is sufficient reason for criminalizing youth behaviors.

Recent examples abound. In South Carolina, a 16-year-old African American student refused to put her cell phone away resulting in the teacher summoning police who "flipped over a teenaged student in her desk, ripped her from it and dragged her across the classroom floor before planting her face on the ground, placing his knee in her back, handcuffing her" (Badash, 2015). According to the report, in spite of the student recently experiencing the loss of both 
parents, the classroom teacher and the school principal fully supported the policeman's response to insubordination. In Irving, Texas, a 12-year-old student of Somalian descent was taken into police custody on charges of bringing a bomb to school, which turned out to be a homemade clock (Biggs, 2015). School and district administration backed the teacher's decision to summon law enforcement in response to what they perceived a potential threat, and the family withdrew the student from the school. In both events, minority students were viewed from a deficit perspective and disciplinary action taken, even though none of the cases involved drugs or weapons as outlined in policy for carrying out school suspensions.

School practice of criminalizing youth from diverse families is deployed through a network of carceral relations where power comes from knowledge derived through observation of conformity to behavioral norms - surveillance equipment, security guards, police intervention, suspension and expulsion, and educational exclusion - the school-to-prison pipeline. Research documents higher likelihood of evoking zero-tolerance and school safety policies in urban schools serving large populations of poor and working-class minority communities where law enforcement are present on school campuses (Gregory \& Weinstein, 2008). Zero Tolerance policies have given public school officials authority to conduct searches on school campuses without warrants, regardless of student privacy, based entirely on probable cause that school safety rules have been violated, thus, overlooking due process and the right to justice (Ayers, Dohrn, \& Ayers, 2001).

The social construction of racial and other differences and how these categories are represented in school policies is a complex intersection of socialization, teaching philosophies, and cultural norms of schools and implementation of policy (Skiba et al., 2006). Research shows a direct correlation between socialization in schools and how disciplinary decisions are enacted. For example, black youth are more likely suspended for disruptive behaviors such as disrespect, making excessive noise, and disobedience - acts that are relative to individual perceptions and not well defined as school violations (Skiba, Michael, Nardo \& Peterson, 2002). On the other hand, youth identified as part of the dominant culture experience disciplinary action for obscene language in the classroom, smoking on campus, and leaving the school without permission-acts that are well-defined violations of school rules.

In educational policy discourse the belief that youth delinquency is a natural condition emerges from the discursive networks that normalize a culture of sameness and pathologize difference. From the historical construction of poverty as synonymous with criminality and the eugenicist order of racial hierarchy to the legal sanction for criminalizing non-conformity, the process of pathologizing difference entails observing, dissecting, labeling, excluding, and normalizing - discursive practices that turn into mechanics of power, knowledge, and privilege. The labels that delineate social, physical, cognitive, affective, neurological or psychological differences actually mask the exclusive authority of normativity to maintain the prevailing social order of power, privilege, and exclusion. Education's hidden curriculum is moved outside the classroom to disciplinary knowledge such as scientific and legal which are held responsible for containing and treating differences.

When incarceration is offered as treatment for being different, there is a double injustice done to youth from diverse families, communities and cultures-first youth are discriminated for being culturally different, then their exclusion is normalized for entry into the prison pipeline. In many ways, the normalization of the school-to-prison pipeline and the socializing function of education are acts of violence that derive meaning from the importance given to rational and binary thinking that position certain forms of difference for incarceration. 
School-to-Prison Pipeline and Youth from Diverse Families

\section{Family Diversity and Difference}

As a former high school teacher in a juvenile prison classroom, and currently serving as a mentor and literacy coach for adjudicated youth, I have been witness to some of the ways youth resist and mediate disciplinary acts of violence and exclusion (Sharma, 2013). My present position as a teacher educator and researcher is an opportunity for me to intervene in this particular historical moment of the criminalization of youth and normalization of the school-toprison pipeline and call for equitable education, without recourse to incarceration. Scholars advocate various approaches, programs and policies to counteract the growing number of students in the school-to-prison pipeline with the goal of educational equity. Some of these include preparing teachers with cross-cultural competencies to work with diversity, redesigning curricula to be inclusive of multiple cultures, increased funding for after-school youth literacy programs, tutoring and mentoring youth identified as at-risk, and reaching out to at-risk youth to enroll in GED programs (Tuck, 2012). While these approaches are well-intentioned, many of them are embedded within the context of specific philosophies, assumptions, and beliefs stemming from a deficit orientation reflected in how key terms and descriptors for diversity are defined, researched, measured, interpreted, generalized, normalized, and communicated.

For example, educational policy has normalized diversity through categories such as race, class, and gender differences that result in unintended exclusions and erasures of large categories of populations living in diverse family arrangements with variations in parenting styles, communication patterns, and literacy practices (Marks, 2000). This is not to ignore the critical importance of race, class, and gender differences in how they create inequities in educational processes and outcomes. Rather, inclusive school policies and practices address complex forms of diversity in the lives of students and their families and recognize diversity as inclusive of complex living arrangements, parenting styles, communication patterns, and home literacies that run counter to the dominant discourse of what constitutes an ideal or universal family (Marsh \& Turner-Vorbeck, 2012).

Policy documents evidence the ideology of the concept of a universal family. Contrary to the universal norm, $25 \%$ of families in the U.S. conform to this family standard; the other $75 \%$ reflect diversity among family structures constituting single mothers, single fathers, step families, shared custodian parents, same sex parents, partners in cohabitation, unmarried single mothers or fathers, grandparents, adopted parents, state custody, foster care, homeless children, migrant parents, children living with migrant communities, intergenerational shared parenting, families supported by non-relatives, and families without parent/s supported by siblings (Allen, Fine \& Demo, 2000; Turner-Vorbeck, 2005; Turner-Vorbeck \& Marsh, 2008). Within these diverse family arrangements, each family experiences a different intersection of structural and emergent factors that influence how members relate to one another, parenting processes, communication within and outside the family, home values and world views, school expectations and involvement in educational processes. In spite of complex family arrangements and practices, the normalizing discourse on parenting is shaped by the image of the ideal or universal family and families that depart are "othered" as deficit, dysfunctional, and neglectful.

When diversity among families is unrecognized and student behaviors and experiences are misunderstood, the school-to-prison pipeline is normalized and education denied as penalty for not conforming to dominant cultural norms. Current interpretations of student behaviors and implementation of policy stigmatizes minority students while leaving their experience of inequities invisible in school policy and practice. What is recommended is examining the 
philosophies and histories behind the policy of sorting, labeling and criminalizing - what is diagnosed as a behavioral or learning disorder is based on assumptions about diversity among families and propagates deficit worldviews of minority cultures. Such a diagnosis is also representative of systemic failure of education to address the cause and effect of social and historical conditions that shape the experience of diversity and difference predicating the experience of the school-to-prison pipeline.

\section{Equity and Social Justice in Education}

By its very existence as a policy and practice, the school-to-prison pipeline is not a subject or object for reform or change or intervention. To reform the school-to-prison pipeline because of the increasing numbers of youth incarcerated or overrepresentation of minority youth is to suggest that there is a hypothetical number of children and youth whose incarceration is morally appropriate and socially just. The question is not how many children should be incarcerated or how the school-to-prison pipeline should be reformed. The critical question is: Who has power to make policy decisions and to what effects? A place to begin addressing inequities and exclusions is the network of government policies, systems of disciplinary knowledge, and institutions with power that make social, economic, and political decisions.

In the past, well-intentioned calls for policy reform for addressing inequities have reinforced the very categories of exclusion they are attempting to address, simultaneously rendering invisible historical and structural injustices and gaps. History resonates with reforms that have led to further exclusion-the Child Savers movement, Juvenile Justice and Delinquency Prevention Act, the No Child Left Behind Act-movements, programs, and reforms operating out of oppressive binaries that discriminate in policy and intent and reinscribe standardized and normed socialization, increase criminalization, and widen inequities. Closely associated with the practice of standardization and educational reform is a complex set of exclusions reminding policy makers of that which is silenced or ignored in school discourse-the experiences of youth from diverse families, communities and cultures. When students from diverse cultures are unable to align with classroom expectations based on standardized norms and dominant behaviors grounded in a Eurocentric bias, the school-to-prison pipeline is realized. When students challenge standardized teaching, their challenges serve as critiques of knowledge privileged in traditional schooling prompting schools to be open and flexible in adopting educational policies. When students resist the status quo in education how policy makers respond to student resistance through policy agendas is significant.

What is called for is equitable education, not incarceration. This is made possible when policies for educational equity include questioning the power dynamics of criminalization and analyzing sedimented disciplinary knowledge that have made the school-to-prison pipeline possible in ideology and practice. How administrators and teachers as representatives of institutional power respond to diversity and difference is critical to education as a practice of equity and social justice. Administrators and teachers have a responsibility in naming inequities and social injustice, participating in the process of youth decarceration, and teaching without recourse to the criminal justice system. The rational forms of knowledge that administrators bring into schools are structured by institutional power relations that define their professional identities, giving them power to reposition students' diverse forms of experiential and cultural knowledge as null. Similarly, teachers use their professional capacities to reproduce social relations in the classroom when they lack critical knowledge and skills for addressing the 
School-to-Prison Pipeline and Youth from Diverse Families

academic needs of students who are from diverse families, communities and cultures, thereby, reinscribing structural and institutional oppression. Conversely, administrators and teachers can acquire the knowledge, awareness, and critical skills to analyze how culturally rooted communication patterns, body language and gestures, when interpreted from a dominant lens construe student behaviors as disruptive, disrespectful, and delinquent.

Social justice goals are realized by interrogating privilege, power, and exclusion and questioning those in power implicated in sustaining their continued deployment with the imperative of equitable education for all students. What is advocated are educational policies, practices, and research that move beyond current thinking toward new conceptual frameworks based on analyses of schooling as a network of socialization and recognizing resistance and challenge as a call for educational equity for social justice. Working toward educational transformation, the following recommendations for policy research, policy structure and school practice focus on critical analyses of the social and institutional context of schools and development of educational policies in collaboration with all stakeholders for implementation of school programs in classroom practice grounded in equitable education and social justice for all students.

\section{Policy-Oriented Research}

\section{Repositioning the Discourse}

- Conduct exploratory and investigative research to develop new concepts, theories, and frameworks that include social, economic, and political determinants of inequities and their consequences guided by the needs of families and communities

- Investigate social processes contingent for making policy decisions that attend to the systemic and the academic needs of local families and communities

- Develop new policy instruments for conceptual alignment with research on social, economic, and political power and the relationship to educational practice

- Analyze policy processes in schools in relation to institutional power, teacher and student identities, and the desired, enacted, and the hidden curriculum

- Conduct meta-analyses on the social and historical construction of educational policy and outcomes in relation to social, economic and other policies

\section{Policy Structure}

- Convene a panel of interdisciplinary professionals and scholars, including families and communities, to develop a focus on policy planning, goals and design from a multisystem approach

- Create a plan for policy review and multisystem evaluation for continuous program development and opportunities for meeting educational goals and outcomes

- Design educational policy across institutional contexts that align with social policies such as family, juvenile justice, and social services

- Update systems measures and categories for trending survey and content data

- Commission a paper on policy planning and its underlying philosophies and principles, as well as projection and outcomes of policy impact in relation to transformation and social justice 


\section{School Practice}

- Develop critical awareness of the goals and role of teacher educators, administrators, and K-12 teachers in the reproduction of institutional policy agendas, school knowledge, and political power

- Innovate teacher educator and K-12 teacher knowledge and skills toward interdisciplinary teaching and classroom practices

- Connect with diverse students, their family backgrounds, communities, and cultures through coursework, ongoing professional development and community engagements

- Orient academic discourse toward political empowerment, opportunities for possibilities, and transformative classroom language inclusive of diversity and difference

- Recognize administrators and K-12 teachers for inclusive social justice practices as factors in classroom evaluation measures

In summary, equitable education through transformative conceptual frameworks has implications for the ways in which theory addresses discrimination, research frames issues critical to diversity and difference, and policy is implemented for social justice. An understanding of socialization in education as social, economic, and political processes is contingent on analysis and evaluation which offers important insights into how socialization, normalization, and discrimination are more than individual responses; they are constructed within and by the broader social, political, and economic networks of power that shape educational policy and practice. This implies working within a broad interdisciplinary approach in which existing conceptual frameworks and intervention models are analyzed and new multisystem approaches to research developed that engage families and communities who experience inequities, discrimination and exclusion. Implications for policy, research, and practice indicate repositioning discourses for equitable education not incarceration, developing policy oriented research that inform program implementation across schools, and implementing school practices that are inclusive of diversity and differences within and among students and families. 
School-to-Prison Pipeline and Youth from Diverse Families

\section{References}

Achinstein, B.\& Barrett, A. (2004). (Re)Framing classroom contexts: How new teachers and mentors view diverse learners and challenges of practice. Teachers College Record, 106(4), 716-746.

Advancement Project (2010). Test, Punish, and Push-Out: How Zero Tolerance and High Stakes Testing Funnel Youth into the School-to-Prison Pipeline. https://b.3cdn.net/advancement/d05cb2181a4545db07_r2im6caqe.pdf

Alexander, M. (2011). The New Jim Crow Mass Incarceration in the Age of Color Blindness. New York, NY: The New Press.

Allen, K.R., Fine, M.A., \& Demo, D.H. (2000). Introduction. In David H. Demo, Katherine R. Allen, and Mark A. Fine (Ed.), Handbook of Family Diversity (pp. 1-14). New York, NY: Oxford University Press.

American Civil Liberties Union, (2015). Beyond Zero Tolerance. Disciplining and Policing in Pennsylvania Public Schools. http://www.aclupa.org/files/6914/3144/0044/2-162015_FINAL_64204_ACLU_ONLINE.pdf

Au, W. (2009). High-stakes testing and discursive control: The triple bind for non-standard student identities. Multicultural Perspectives, 11(2), 65-71.

Ayers, W., Dorhn, B., \& Ayers, R. (2001). Zero tolerance: Resisting the drive for punishment in our schools. New York, NY: The New Press.

Badash, D. (2015). Sheriff: Female Student Who Was Tossed By Cop Punched Him, He Is 'Dating An African American Woman' http:/www.thenewcivilrights movement.com/davidbadash/south_carolina_sheriff_teenag ed_student_who_was_tossed_by_police_officer_punched_him

Baker, B. (2002). The hunt for disability: The new eugenics and the normalization of school children. Teachers College Record. www.tcrecord.org/PrintContent.asp?ContentID=10895

Biggs, J. (2015). 14-Year-Old Boy Arrested For Bringing Homemade Clock To School. http://techcrunch.com/2015/09/16/14-year-old-boy-arrested-for-bringing-homemadeclock-to-school/

Brigham, C. (1923). A study of American Intelligence. Princeton, NJ: Princeton University Press.

Children's Defense Fund (2007). "Cradle to Prison Pipeline Initiative." http://www.childrensdefense.org/site/PageServer?pagename $=c 2 p p$

Children's Defense Fund, (2011). The State of America's Children. www.childrensdefensefund.org 
Coggshall, J. G., \& Ott, A. (with Lasagna, M.). (2010). Retaining teacher talent: Convergence and contradictions in teachers' perceptions of policy reform ideas. Naperville, IL: Learning Point Associates and New York: Public Agenda. http://www.learningpt.org/expertise/educatorquality/genY/Convergence_Contradiction.p df

Council of Chief State School Officers, (2015). Common Core State Standards. http://www.corestandards.org/about-the-standards/

Coulter, E. (1913). The Children in the Shadow. New York: Mcbride, Nast.

Dohrn, B. (2002). The school, the child, and the court. In Margaret K. Rosenheim, Franklin E. Zimring, David S. Tanenhaus, \& Bernadine Dohrn (Eds.), A century of juvenile justice (pp. 267-309). Chicago, IL: The University of Chicago Press.

Fabelo, T., Thompson, M. D., Plotkin, M., Carmichael, D., Marchbanks, M. P., \& Booth, E. A. (2011). Breaking schools' rules: A statewide study of how school discipline relates to students' success and juvenile justice involvement. College Station, TX: Public Policy Research Institute.

Foucault, M. (1972a). Archaeology of Knowledge (Alan Sheridan, Trans.). New York, NY: Pantheon.

Foucault, M. (1972b). Power/Knowledge: Selected Interviews and Other Writings (C. Gordon, ed.). New York: Pantheon Books.

Foucault, M. (1977). Discipline and Punish. New York: Vintage Books.

Foucault, M. (1984). Nietzsche, genealogy, history. In P. Rabinow (Ed.), The Foucault Reader (pp. 76-100). New York: Pantheon.

Galton, F. (1881). Inquiries into Human Faculty and its Development. London: Everyman's Library.

Gregory, A., \& Weinstein, R. S. (2008). The discipline gap and African Americans: Defiance or cooperation in the high school classroom. Journal of School Psychology, 46, 455-475.

Jack, J. \& Sludden, J. (2013). School Closings in Philadelphia. Urban Education, 10(1). http://www.urbaned journal.org/archive/volume-10-issue-1-summer-2013/schoolclosings-philadelphia

Jacoby, S. (2008). The Age of American Unreason. New York, NY: Random House Inc.

Kerlin, I. N. (1890). The moral imbecile. Proceedings of the National Conference of Charities and Correction (PNCCC) in The ANNALS of the American Academy of Political and Social Science 1(2), 244-50. 
School-to-Prison Pipeline and Youth from Diverse Families

Lemann, N. (1999). Secrets of the SAT. Frontline. http:/www.pbs.org/wgbh/pages/frontline/shows/sats/interviews/lemann.html

Lipman, P. (2011). The New Political Economy of Urban Education. New York, NY: Routledge.

Lombroso, C. (1893). Crime, its Causes and Remedies (H. P. Horton, Trans.). Boston, MA: Little, Brown.

Mack, J. W. (1909). The Juvenile Court. Harvard Law Review, 23(2), 104-22.

Madkins, T. C. (2011). The black teacher shortage: A literature review of historical and contemporary trends. Journal of Negro Education, 80(3), 417-427.

Marks, S.R. (2000). Testing out the lessons of the 1960s: Family diversity and family privilege. Journal of Marriage and the Family, 62, 609-622.

Marsh, M. \& Turner-Vorbeck, T. (2012). Education and family diversity. In James A. Banks (Ed.), Encyclopedia of Diversity in Education (pp. 741-743). Thousand Oaks, CA: Sage Publications.

Meiners, E. (2007). Right to be Hostile: Schools, Prisons, and the making of Public Enemies. New York, NY: Routledge.

Meiners, E. (2015). Trouble with the child in the carceral state. Social Justice, 41(3). 120145.

Program Training Administrator. (2009). Juvenile Facility Training Handbook. Muncie, IN: Correctional Management Company.

Said, E. W. (1979). Orientalism. New York: Random House.

Sharma, S. (2010). Contesting institutional discourse to create new possibilities for understanding lived experience: Life-stories of young women behind bars, rehabilitation, and education. Race, Ethnicity and Education 13(3). 327-347.

Sharma, S. (2013). Girls Behind Bars: Reclaiming Education in Transformative Spaces. New York, NY: Bloomsbury Publishing Plc.

Simmons, L. (2015). Profiting from punishment: Public education and the school security market. Social Justice, 41(4), 81-95.

Skiba, R. J., Michael, R. S., Nardo, A.C. \& Peterson, R. L. (2002). The color of discipline: Sources of racial and gender disproportionality in school punishment. The Urban Review, 34(4), 317-342. 
Skiba, R., Reynolds, C. R., Graham, S., Sheras, P., Conoley, J. C. \& Garcia-Vazquez, E. (2006). Are Zero Tolerance Policies Effective in the Schools? An Evidentiary Review and Recommendations. A Report by the American Psychological Association Zero Tolerance Task Force.

Snyder, H. N., and Sickmund, M. (2006). Juvenile Offenders and Victims: 2006 National Report. Office of Juvenile Justice and Delinquency Prevention (OJJDP). Office of Justice Program. U.S. Department of Justice. www.ncjrs.gov/pdffiles1/ojjdp/221338

Springer, D. W. \& Roberts, A. R. (2011). Juvenile Justice and Delinquency. Sudbury, MA: Jones and Bartlett Publishers.

Stullken, E. H. (1956). Misconceptions about juvenile delinquency. The Journal of Criminal Law, Criminology, and Police Science 46(6), 833-42.

Sullivan, A.L., Klingbeil, David A., Van Norman, E. R. (2013). Beyond behavior: Multilevel analysis of the influence of sociodemographics and school characteristics on students' risk of suspension. School Psychology Review. 42(1), 99-114.

Tuck, E. (2012). Urban Youth and School Pushout: Gateways, Get-aways, and the GED. New York, NY: Routledge.

Turner-Vorbeck, T. (2005). Expanding multicultural education to include family diversity. Multicultural Education, 13(2), 6-10.

Turner-Vorbeck, T., \& Miller Marsh, M. (2008). Other Kinds of Families. New York, NY: Teachers College Press.

United States Department of Education. (2001). No Child Left Behind Act Executive Summary. http://www.ed.gov/nclb/overview/intro/execsumm.pdf

Winn, M. \& Behizadeh, N. (2011). The right to be literate: Literacy, education, and the schoolto-prison pipeline. Review of Research in Education. Vol. 35, 147-173. 